\title{
The Viscometric and Light-Scattering Determination of Dilute Solution Properties of Cellulose Diacetate
}

\author{
Kenji Kamide, Toshikazu TeraKawa, and Yukio Mryazaki \\ Textile Research Laboratory, Asahi Chemical Industry Co., Ltd., \\ Takatsuki, Osaka 569, Japan.
}

(Received June 30, 1978)

\begin{abstract}
Eleven cellulose diacetate (CDA) fractions each with a combined acetic acid content of $55.5 \mathrm{wt} \%$ and a ratio of weight- to number-average molecular weight $M_{w} / M_{n}=1.2-1.3$ were carefully prepared. These fractions were not contaminated by gellike materials. Dilute solution properties were measured in acetone and tetrahydrofuran (THF) at $25^{\circ} \mathrm{C}$ by a light scattering method, membrane osmometry, viscometry and gel permeation chromatography. The following Mark-Houwink-Sakurada (MHS) equations were established for CDA : $[\eta]=0.133 M_{w}{ }^{0.816}$ in acetone and $[\eta]=0.0513 M_{w}{ }^{0.688}$ in THF. The draining parameter $X$, as determined by various methods, was found to be less than four in acetone, and less than eight in THF. The molecular weight dependence of Flory's viscosity parameters $\Phi$, expressed as $a_{\Phi}(=\mathrm{d} \ln \Phi / \mathrm{d} \ln M)$, was 0,716 and 0.105 in acetone and THF, respectively. The CDA polymer chain is gaussian in THF, but is not so in acetone. That is, $a_{2}\left(=\mathrm{d} \ln \left(\left\langle S^{2}\right\rangle_{0} / M\right) / \mathrm{d} \ln M\right.$, where $\left\langle S^{2}\right\rangle_{0}$ is the mean-square radius of gyration in the unperturbed state) was -0.471 in acetone. The unperturbed chain dimensions $A\left(=\left(6\left\langle S^{2}\right\rangle_{0} / M\right)^{1 / 2}\right)$ obtained by methods in which $a_{2}$ and $a_{\Phi}$ (if necessary) were taken into account, agree well with each other, as the theory predicts. The value of $\mathrm{A}$ was 1.73 in acetone and 1.23 in THF. CDA is a typical semi-flexible polymer. The experimental second virial coefficient $A_{2}$ can be reasonably explained in terms of the theory, in which $a_{2}$ and $a_{\Phi}$ are considered.
\end{abstract}

KEY WORDS Cellulose Diacetate / Mark-Houwink-Sakurada Equation / Draining Parameter / Unperturbed Chain Dimension / Dilute Solution Property /

Cellulose diacetate (CDA) has a long history of research, corresponding to it's industrial importance. As far as dilute solution properties are concerned, the viscometric and membrane osmometric (MO) techniques have been predominantly used with very few exception. ${ }^{1,2}$

Numerous Mark-Houwink-Sakurada (MHS) equations between the limiting viscosity number $[\eta]$ and the molecular weight $M$, generally expressed as

$$
[\eta]=K_{\mathrm{m}} M^{a}
$$

have been proposed for CDA. ${ }^{3}$ In eq $1, K_{\mathrm{m}}$ and $a$ are constants characteristic of a given polymersolvent system at a given temperature and for a specific molecular weight range concerned. The number-average molecular weight $M_{n}$ has been used in eq 1 for CDA fractions having rather wide molecular weight distribution (MWD), isolated by successive precipitational fractionation (SPF). Thus, no great confidence can be placed in the accuracy of the parameters $K_{\mathrm{m}}$ and $a$ in eq 1 for CDA in solvents (especially, acetone).

The experimental difficulty was encountered for light scattering (LS) measurements of CDA even in a good solvent, owing to contamination by gel-like materials in the solutions. ${ }^{4,5}$ Kamide and his coworkers have studied extensively the nature of prehump (i.e., gel) in gel permeation chromatogram (GPC) obtained for CDA in acetone and tetrahydrofuran (THF) $)^{4,5}$ and found the preparation procedure of CDA which produces no prehump when dissolved in the solvents.

In this paper, we have attempted (1) to study, 
by viscometry, MO, GPC, and LS, the dilute solution properties of $\mathrm{CDA}$ fractions, fractionated from a carefully prepared original polymer, by successive solutional fractionation (SSF), which was experimentally and theoretically verified to give fractions with a very narrow MWD, ${ }^{7-11}$ and (2) to evaluate the molecular parameters such as the partially free draining effect and unperturbed chain dimensions (UCD) from the dilute solution properties determined here.

\section{EXPERIMENTAL}

\section{Polymer Sample and Solvents}

High $\alpha$-cellulose pulp, trade name Raycrod XG-LD, manufactured by ITT Rayonier Inc. (USA) $(\alpha$-cellulose $95.4 \mathrm{wt} \%$, $\beta$-cellulose $3.8 \mathrm{wt} \%$, pentosan $1.0 \mathrm{wt} \%$, ash $0.03 \mathrm{wt} \%$, the viscosityaverage degree of polymerization $P_{v}=1189$ ) was employed as a starting material. The cellulose pulp was converted into cellulose triacetate (CTA) by using the acetic anhydride-acetic acid-sulfuric acid system. CTA thus prepared was hydrolyzed with magnesium carbonate to yield CDA of 55.6-wt \% combined acetic acid content (AAC).

According to the authors' more than twenty years of experience in the study of cellulose derivatives, in order to prepare CDA solution which is absolutely free from the gel-like materials, it is of prime importance to choose mild conditions of acetylation reaction, followed by a very careful hydrolysis reaction and to treat whole CDA polymers thus obtained with a weak acid, decomposing the cellulose acetate having a large weightaverage molecular weight $M_{w}$, which contains a sulfuric acid group, sodium and calcium (particle size in acetone, $80-300 \mathrm{~nm}$ as determined by prehump II in GPC curve) and then to extract the component of cellulose diacetate with higher AAC (57-58 wt \%) (partiale size, $150-450 \mathrm{~nm}$ in acetone, as detected by prehump I in GPC) with dichloromethane. It should be remembered that almost all previous investigators have used commercial products, which were not satisfactory for light scattering measurements.

Spectroscopy grade acetone and THF were further purified and distilled immediately before use. Tetrachloroethane (TCE) was reagent grade and used as received.

\section{Fractionation}

A solution of the original polymer in acetone was fractionated at $30^{\circ} \mathrm{C}$ by using ethanol as precipitant, according to SSF into 16 to 21 fractions. The polymer volume fraction $v_{\mathrm{p}}{ }^{0}$ of the solution at the first fractionation step, from which the phase separation occurs, was $2.1 \%$. The detailed procedure of SSF experiments will be reported elsewhere. ${ }^{12}$. The SSF run was duplicated to obtain enough fractions for further study (the first run was designated as EF-2 and the second run, EF-3). The combined acetic acid content of fractions was determined by infra-red spectroscopic method. ${ }^{4}$ Of the resulting thirty seven fractions, eleven were chosen for further study, excluding GPC.

\section{Light Scattering}

The stock solution of CDA fractions was made by mechanical agitation at a concentration of approximately $5 \cdot 10^{-3} \mathrm{~g} / \mathrm{cm}^{3}$ with acetone or THF as solvent. The solutions of high molecular weight CDA fractions were cooled down below $-70^{\circ} \mathrm{C}$ and subsequently warmed at $30^{\circ} \mathrm{C}$ in order to make dissolution complete. After these solutions were centrifuged at $29000 \mathrm{~g}$ for $1 \mathrm{~h}$, the middle layer portions were collected by a microsyringe. The concentrations of the solutions were adjusted by adding pure solvent to the collected solutions which were then made to pass through a 200-nm Alpha metricel filter (Alpha -8), manufactured by Gelman Instrument Co. (GBR), directly into the cyclindrical light scattering cell. The solutions were allowed to stand at room temperature overnight. The solutions and solvents were thus free from dust and gels.

Light scattering measurements on CDA in acetone and in THF were carried out in a ShimadzuBrice type light scattering photometer model PG21 (for EF-2 series fractions) and in a FICA model 42000 photo gonio diffusiometer (for EF-3 series fractions).

Unpolarized light with wave length $\lambda=546$ and $436 \mathrm{~nm}$ were utilized in acetone and THF respectively. Cylindrical cells capped with a close fitting stainless stopper were employed in order to minimize evaporation of the solvent during measurements and were immersed in a bath containing benzene at $25 \pm 0.2^{\circ} \mathrm{C}$. No scatter dissymmetry was observed; that is, in all cases, the 
dissymmetry factor was always less than 1.02 . The concentration range was 1.25 to $0.5 \times 10^{-3} \mathrm{~g}$ / $\mathrm{cm}^{3}$. The apparatus were calibrated with benzene, using unpolarized $90^{\circ}$ scattering light and taking the Rayleigh ratio $R_{90}=16.3 \cdot 10^{-6} \mathrm{~cm}^{-1}$ at $\lambda=$ $546 \mathrm{~nm}$ and $48.5 \cdot 10^{-6} \mathrm{~cm}^{-1}$ at $436 \mathrm{~nm}$. Scattered intensities were measured at various angle from $37.5^{\circ}$ to $142.5^{\circ}$.

The specific refractive index increment $\mathrm{d} n / \mathrm{d} c$ on solutions of CDA in acetone and in THF was determined by a Shimadzu differential refractometer model DR-4 at $25 \pm 0.2^{\circ} \mathrm{C}$ at a wave length of 546 and $436 \mathrm{~nm}$. With this instrument, the refractive index increment measurements are accurate to $\pm 1.3 \times 10^{-5} \mathrm{~cm}^{3} / \mathrm{g}$. The $\mathrm{d} n / \mathrm{d} c$ value obtained for CDA solutions was $0.109 \mathrm{~cm}^{3} / \mathrm{g}$ in acetone at $\lambda=546 \mathrm{~nm}$ and $0.068 \mathrm{~cm}^{3} / \mathrm{g}$ in THF at $\lambda=436 \mathrm{~nm}$. These values were found for three different fractions and two whole polymers with $\mathrm{AAC}=54.2-55.6 \mathrm{wt} \%$. The $\mathrm{d} n / \mathrm{d} c$ value for these systems are in fairly good agreement with the values found by Stein and Doty ${ }^{1}(0.104-0.116$ in acetone) and by Tanner and Berry ${ }^{2}$ ( $c a .0 .11$ (from Figure 2 of ref 2) in acetone and 0.0710 in THF). The refractive index of the solvents were measured on a Hitachi Abbe refractometer.

Zimm plots were made of $K c / R_{\theta}$ against $\sin ^{2} \theta /$ $2+k c$ where symbols have their usual meaning. The second virial coefficient $A_{2}$, the $z$-average radius of gyration $\left\langle\mathrm{S}^{2}\right\rangle_{z}^{1 / 2}$ and $M_{w}$ were determined from the plots in the usual way.

\section{Membrane Osmometer}

The Hewlett Packard high-speed membrane osmometer model 502 was used for the osmometric measurement in THF and TCE. The membrane was a Selectron membrane filter type 0-8, manufactured by Schleicher and Schuell Inc. (DBR). $M_{n}$ and $A_{2}$ were obtained from the linear part of a plot of $\pi / c$ vs. $c$ as intercept and slope, respectively. The diffusion of solute was not detected experimentally by comparing solvent reference values before and after the measurement.

\section{Solution Viscosity}

Viscosity measurements were made by a modified Ubbelohde suspension type viscometer in a constant bath controlled to $\pm 0.01^{\circ} \mathrm{C}$. [ $\left.\eta\right]$ ] was determined from the reduced viscosity at four or five concentrations by extrapolation of $\eta_{\mathrm{sp}} / c$ to infinite dilution. In this case, the kinetic energy correction was very small.

\section{Gel-Permeation Chromatography}

A Shimadzu gel-permeation chromatography model $1 \mathrm{~A}$ was used. This instrument was filled with a five columns analytical set of cross-linked polystyrene gels: Toyo-soda G-2000S, G-3000S, G-4000S, G-6000S, and G-6000S. THF was used as the eluting solvent at a flow rate of $1 \mathrm{~cm}^{3} / \mathrm{min}$. The operating temperature was $25 \pm 2^{\circ} \mathrm{C}$. For the calibration of GPC, eleven well-defined CDA fractions were used.

\section{RESULTS AND DISCUSSION}

\section{Molecular Weight and Molecular Weight Distribu- tion of CDA Fractions}

The acetic acid content for series of EF-2 and EF-3 fractions lies between $55.5 \pm 1.0 \mathrm{wt} \%$, independent of $M_{w}$, indicating that the fractionation with respect to the degree of substitution (DS) does not occur during the SSF run.

The prehump of the GPC curve, which was readily ovserved for CDA, prepared by the conventional manner, was not detected significantly in the present case. This strongly suggests that all the CDA molecule exist in a molecularly dispersed state in the solution, and this strongly supports the excellent agreement of $M_{w}$ by LS in acetone with $M_{w}$ by LS in THF and $M_{w}$ by GPC, (THF).

In the evaluation of the molecular weight distribution of the CDA fractions, the plot of $M_{w}$ (by LS in acetone) $v s$. eluent volume $V_{\mathrm{e}}$ was extrapolated linearly for both $M_{w}$ sides. $M_{w}$ and $M_{n}$ as calculated from MWD curve thus obtained are tabulated in Table I.

The polydispersity parameter $M_{w} / M_{n}$, as determined by GPC, of the fractions is graphed in Figure 1 as open mark as a function of their $M_{w}$. The open circle and open triangle correspond to the first (EF-2) and second (EF-3) runs, respectively. Good reproducibility of SSF experiment is confirmed experimentally. Except for a few initial fractions $M_{w} / M_{n}$ of the fractions can be considered as actually constant (1.2-1.3), independent of $M_{w}$. Figure 1 includes in a closed circles the data of Tanner and Berry, ${ }^{2}$ who fractionated precipitationally commercial $\mathrm{CDA}(\mathrm{DS}=$ 


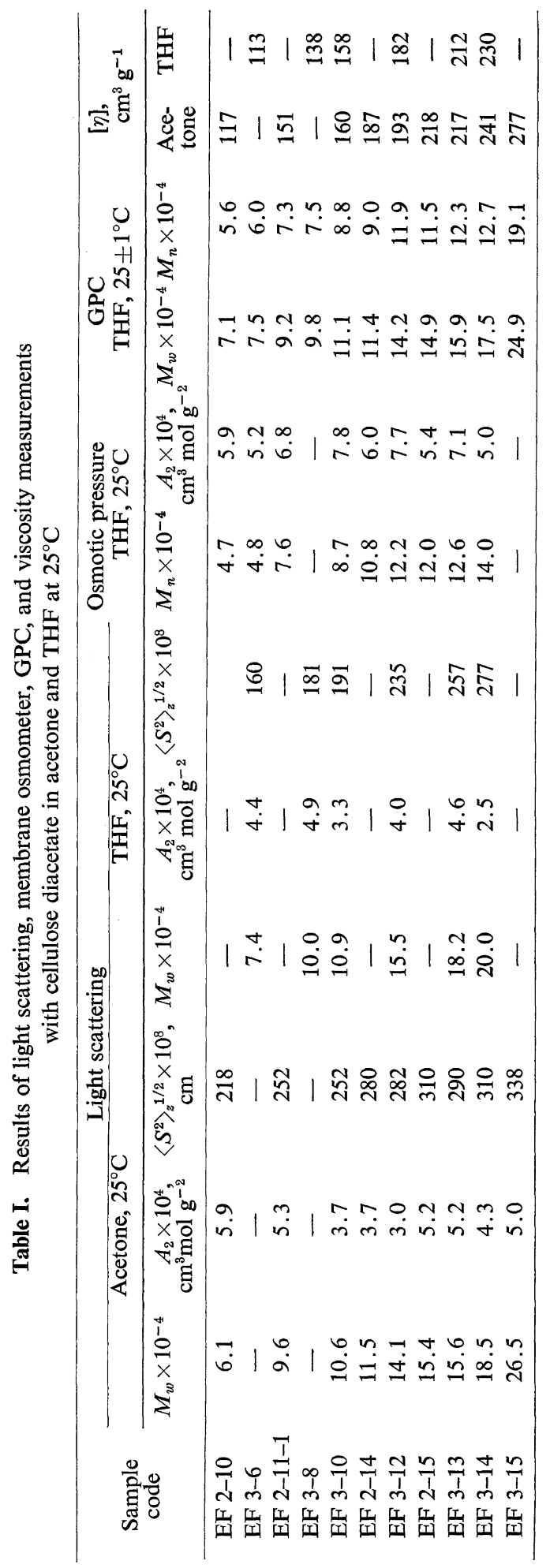

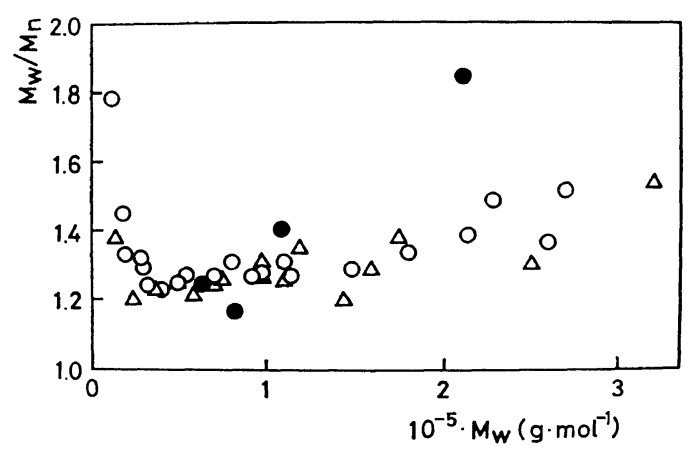

Figure 1. Variation of the ratio $M_{w} / M_{n}$ of cellulose diacetate fractions with $M_{w}$ : $\bigcirc$, successive solutional fractionation (SSF) run (EF-2), initial polymer volume fraction $v_{\mathrm{p}}{ }^{0}=2.1 \%$, total number of fractions $n_{\mathrm{t}}=21 ;, \triangle \mathrm{SSF}$ run $(\mathrm{EF}-3), v_{\mathrm{p}}{ }^{0}=2.1 \%, n_{\mathrm{t}}=16 ; 0$, successive precipitational fractionation (SPF) run by Tanner and Berry ${ }^{2}, v_{\mathrm{p}}{ }^{0}=0.15 \%, n_{\mathrm{t}}=20 . M_{w}$ and $M_{n}$ are determined by gel-permeation chromatography.

2.45) by using the same solvent-nonsolvent pair as that employed in this study. In spite of the very severe operating conditions used by them (i.e., $v_{\mathrm{p}}{ }^{0}=0.3 \%$ and total number of fractions in a run $n_{\mathrm{t}}=19$ ), the polydispersity of the fractions isolated by SPF is larger than that of the fractions by SSF, showing a remarkable $M_{w}$ dependence as the theory predicts. As a result, the fractions employed here have probably the narrowest MWD among cellulose derivative samples, which have been used before for the solution study.

A typical Zimm plot is demonstrated in Figure 2. The plot can be reasonably represented by nondistorted diamond shape, exhibiting no downward curvature. The double extrapolations $\lim _{c \rightarrow 0} K c / R_{\theta}$ and $\lim _{\theta \rightarrow 0} K c / R_{\theta}$ cut the ordinate axis at the same point. Although the highest fractions (EF-2-16 and EF-3-21) were completely soluble in acetone and THF, their Zimm plot revealed a downward curvature at lower angle and, so we discarded them.

The results of LS, MO, GPC (in part), and viscometry measurements are recorded in Table $\mathrm{I}$. Two different LS apparatus always yielded consistent results (Compare the data between two fractions: EF-2-15 and EF-3-13). $M_{w}$ as determined by LS in acetone is in good agreement with $M_{w}$ by LS in THF and with $M_{w}$ by GPC 


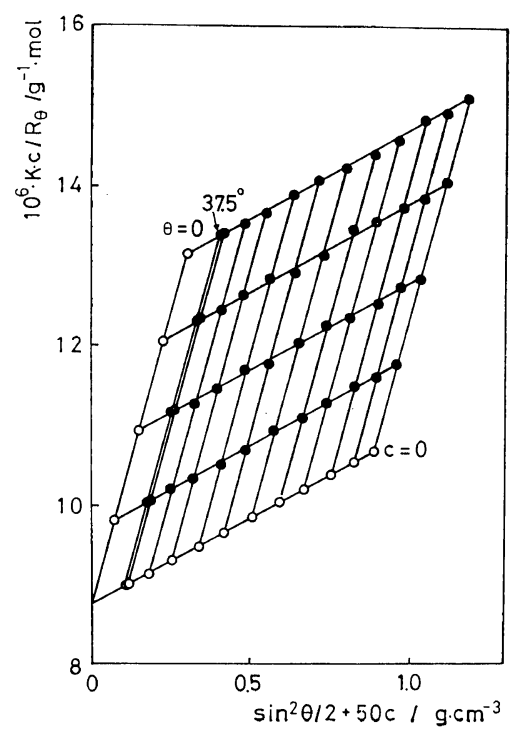

Figure 2. Zimm plot of a cellulose diacetate fraction EF 2-14 in acetone at $25^{\circ} \mathrm{C}$; unpolarized incident light wave length $\lambda=546 \mathrm{~nm}$. The symbols have their usual meaning.

in THF at least in the range of $M_{w}$ from 6 to $26 \times 10^{4} . \quad M_{n}$ as determined by MO in THF agrees also with $M_{n}$ by GPC in THF. The above coincidence definitely verifies the reliability of the methods adopted for the molecular weight determination and indicates that there is no association of CDA in acetone and THF, if the polymer samples are very carefully prepared. Tanner and Berry used for the light scattering measurements a mixed solvent, (THF-trifluoroethanol (TFE), 50: 50 volume ratio), which gave solutions as free from aggregation as any system they studied. ${ }^{2}$ However it should be pointed out that the ratio of $M_{w}$ as determined by LS in a mixed solvent to $M_{w}$ by GPC in THF $\left(M_{\mathrm{GPC}}\right.$ according to their notation) for the same polymer deviates very widely from unity in the range $M_{w}$ by $\mathrm{GPC} \geq 15.4 \times 10^{4}$. It seems to us that the disparity of $M_{w}$ by $\mathrm{LS} / M_{w}$ by GPC from unity means some aggregation even in the mixed solvent.

The value of $M_{n}$ determined by MO in TCE decreases with increasing temperature, approaching $M_{n}$ by MO in THF as is shown in Figure 3. CDA molecule has considerable tendency to yield associated aggregates in poor solvents, like TCE below $70^{\circ} \mathrm{C}$. Ikeda and Kawaguchi, ${ }^{13}$ who over-

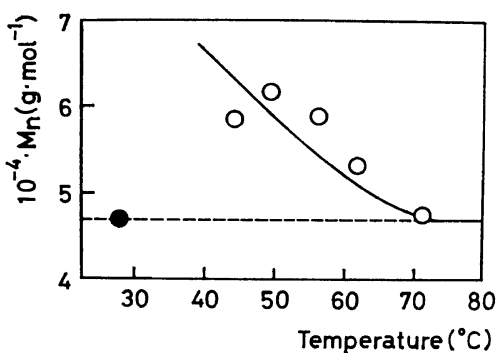

Figure 3. Plot of apparent number-average molecular weight $M_{n}$, as determined by membrane osmometry, for cellulose diacetate fraction EF 2-10 in tetrachloroethane (TCE) against the temperature of measurement: $\bigcirc, M_{n}$ in TCE; $\bullet, M_{n}$ in tetrahydrofuran (THF).

looked this phenomena for CDA in TCE, insisted that TCE at $56.5^{\circ} \mathrm{C}$ acts as a Flory's theta solvent for CDA, in which $A_{2}$ by membrane osmometry vanishes.

\section{Mark-Houwink-Sakurada Equations}

The Huggins constant $k^{\prime}$ increases continuously with $M_{w}$ from 0.4 to 0.6 in acetone and THF. $\log -\log$ plots of [ $\eta] v s . M_{w}$ for CDA in both solvents at $25^{\circ} \mathrm{C}$ are graphed in Figure 4, where $M_{w}$ by LS in acetone is used for [ $\left.\eta\right]$ in acetone and $M_{w}$ by LS in THF is employed for [ $\left.\eta\right]$ in THF. From this figure, the following MHS

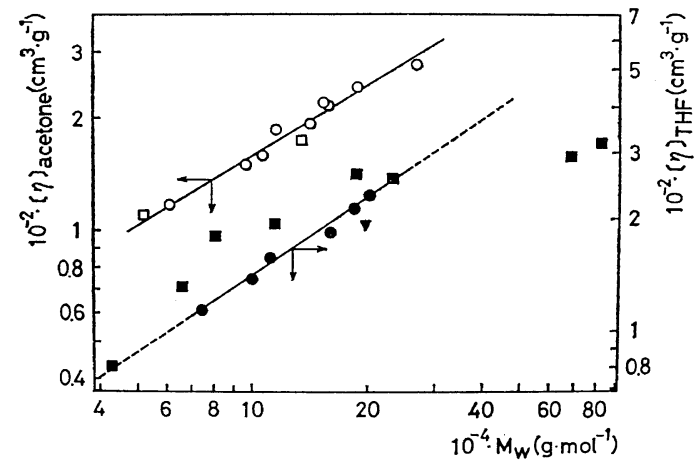

Figure 4. Log-log plot of limiting viscosity number [ $\eta]$ against the weight-average molecular weight $M_{w}$ for cellulose diacetate in acetone at $25^{\circ} \mathrm{C}$ (open mark)

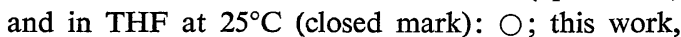
$\square$, data from Stein and Doty's work ${ }^{1}$; and $\mathbf{\nabla}$, data from Tanner and Berry. ${ }^{2} \quad M_{w}$ is determined by light scattering method in acetone ( $O$ and $\square$ ), in THF ( $\bullet$ and $\nabla$ ) and in a mixed solvent ( $\mathbf{(})$. 
equations are established by the least square methods

$$
[\eta]=0.133 M_{w}^{0.616} \text { in acetone at } 25^{\circ} \mathrm{C}
$$

$\left(6.1 \times 10^{4} \leq M_{w} \leq 26.5 \times 10^{4}\right.$, sample number 9)

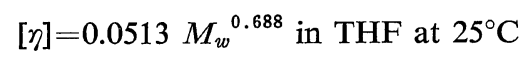

$\left(7.4 \times 10^{4} \leq M_{w} \leq 30.0 \times 10^{4}\right.$, sample number 6)

The value of $a$ for acetone solution, as calculated from $M_{n}$, is 0.643 . Among the five fractions employed for Stein and Doty's LS study, ${ }^{1}$ two fractions (23B and 31B) were used for the viscosity measurements in acetone at $25^{\circ} \mathrm{C}$ by Badgley and Mark. ${ }^{14}$ The data $\left([\eta]\right.$ and $\left.M_{w}\right)$ for these two fractions are plotted in Figure 4, for comparison as open rectangular. These data fall reasonably on the experimental line [eq a]. Also included are the data points obtained by Tanner and Berry for CDA (DS=2.45) in $\mathrm{THF}^{2}$ Here, $M_{w}$ as determined by LS in a mixed solvent (closed rectangular) or in THF (closed triangle) is employed. Their data points scatter widely around eq $b$, indicating a large experimental error, particularly, in the higher $M_{w}$ range.

The above equations (eq a and b) are obtained for the samples with $M_{w} / M_{n}=1.2-1.38$. Hence, equations can be readily converted into those for monodisperse samples. The results are

$$
[\eta]=0.136 M^{0.616} \text { in acetone at } 25^{\circ} \mathrm{C}
$$
and

$$
\text { [ } \eta]=0.0524 M^{0.688} \text { in THF at } 25^{\circ} \mathrm{C}
$$

In deriving eq $\mathrm{a}^{\prime}$ and $\mathrm{b}^{\prime}$, the Schulz-Zimm distribution is assumed for the CDA fractions.

Up to now, numerous different MHS equations for CDA in acetone have been published by Kraemer ${ }^{15}$ Bartovics and Mark, ${ }^{16}$ Sookne and Harris, ${ }^{17}$ Badgley and Mark, ${ }^{14}$ Philipp and Bjork, ${ }^{18}$ Cumberbirch and Harland, ${ }^{19}$ Moore and Tidswell, ${ }^{20}$ and Ikeda and Kawaguchi, ${ }^{13}$ who employed $M_{n}$ except for Kraemer. All experimental equations lie to the left of eq $\mathrm{a}^{\prime}$, when $[\eta]$ and $M$ are double-logarithmically plotted, and the wide variation of $K_{\mathrm{m}}$ and $a$ of those equations can be reasonably explained by the polydispersity effect of the samples. It is noted that the molecular weight dependence of the polydispersity of the polymer samples utilized in literature made the exponent a large as compared with 0.616 obtained here.

\section{Second Virial Coefficient and Radius of Gyration}

The molecular weight dependence of $A_{2}$, as determined by LS, is plotted in Figure 5, where data of CDA (DS=2.43) in acetone from Stein and Doty's work ${ }^{1}$ are also included as an open triangle. $A_{2}$ for CDA in acetone and in THF is of a magnitude order of $10^{-4} \mathrm{~cm}^{3} \mathrm{~mol} \mathrm{~g}^{-2}$, practically independent of $M_{w}$ within a rather large experimental uncertainity as found for various cellulose, amylose and their derivatives. The value of $A_{2}$ as determined by LS in THF is somewhat (about $40-50 \%$ ) larger than that by MO.

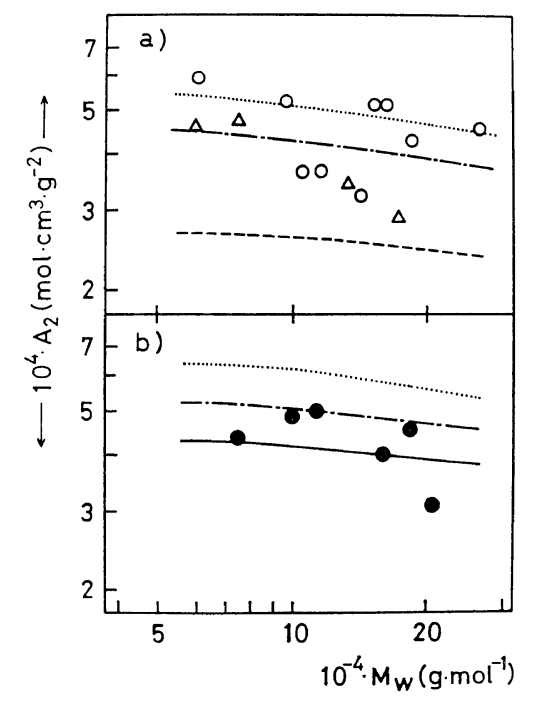

Figure 5. Molecular weight dependence of the second virial coefficient $A_{2}$ for cellulose diacetate solutions in acetone (a) and in tetrahydrofuran (b) at $25^{\circ} \mathrm{C}: \mathrm{O}$, cellulose diacetate (degree of substitution $\mathrm{DS}=2.45$ ) in acetone (this work); $\triangle$, cellulose diacetate (DS $=$ $2.45)$ in acetone ${ }^{1} ; 0$, cellulose diacetate $(D S=2.45)$ in THF (this work). Lines are calculated by eq 32 and 5 from $\mathrm{A}$ (or $K_{0}$ ) and $\mathrm{B}$, which are estimated by Methods 2C (full line), 2D (broken line), 2E (dotted line), and $2 \mathrm{G}$ (chain line), and the experimental $\left\langle\mathbf{S}^{2}\right\rangle_{w}$ data.

Figure 6 displays the molecular weight dependence of $\left\langle\mathrm{S}^{2}\right\rangle_{2}^{1 / 2}$ for CDA in acetone and THF. In the figure, the data of Stein and Doty ${ }^{1}$ on CDA in acetone and of Tanner and Berry on CDA in THF at $25^{\circ} \mathrm{C}$ and TFE at $20^{\circ} \mathrm{C}$ are also included for the sake of comparison.

The molecular weight dependence of $\left\langle\mathrm{S}^{2}\right\rangle_{z}{ }^{1 / 2}$ of CDA in acetone from Stein and Doty's work 


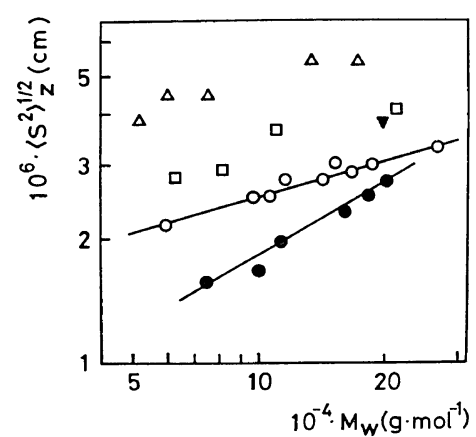

Figure 6. Molecular weight dependence of the radius of gyration $\left\langle\mathrm{S}^{2}\right\rangle_{z}{ }^{1 / 2}$ for cellulose diacetate solution: $\bigcirc$, acetone (this work); $\triangle$, acetone (Stein and Doty) ${ }^{1}$; $\square$, trifluoroethanol (Tanner and Berry) ${ }^{2}$; $\odot$, tetrahydrofuran (THF) (this work); $\boldsymbol{\nabla}$, THF (Tanner and Berry). ${ }^{2}$

(see, $\lambda^{\prime}$ in eq 29) is of the same order as that obtained by us and the absolute magnitude of $[\eta]$ in acetone is almost the same as that in this paper (see, Figure 4), compared at the same molecular weight. However, the absolute magnitude of $\left\langle\mathrm{S}^{2}\right\rangle_{z}{ }^{1 / 2}$ by Stein and Doty is about two times larger than ours. The accuracy of Stein and Doty's work was pointed out by Doty, et al., ${ }^{21}$ to be in doubt due to colloidal contaminations. The value of $\left\langle\mathrm{S}^{2}\right\rangle_{z}{ }^{1 / 2}$ of CDA in THF from Tanner and Berry's work ${ }^{2}$ (fraction $3 ; 2$ ) is about $50 \%$ larger than that obtained here of the polymer with the same $M_{w}$, but [ $\left.\eta\right]$ value of the fraction is about $20 \%$ smaller than [ $\eta$ ] calculated from eq $\mathrm{a}^{\prime} . \quad\left\langle\mathrm{S}^{2}\right\rangle_{z}{ }^{1 / 2}$ is related to $M_{w}$ by the relation

$$
\left\langle\mathrm{S}^{2}\right\rangle_{z}{ }^{1 / 2}=7.39 \times 10^{-8} M_{w}{ }^{0.308}(\mathrm{~cm})
$$

in acetone at $25^{\circ} \mathrm{C}$

and

$$
\left\langle\mathrm{S}^{2}\right\rangle_{z}{ }^{1 / 2}=2.99 \times 10^{-9} M_{w}{ }^{0.558}(\mathrm{~cm})
$$

in $\mathrm{THF}$ at $25^{\circ} \mathrm{C}$

\section{Draining Effect Parameter}

The draining effect parameter $X$, determined by eq $2^{22}$

$$
X=(1 / 2)(6 / \pi)^{1 / 2}\left(b / a^{\prime}\right) N^{1 / 2}
$$

was evaluated according to the methods used in previous papers $^{23,24}$ ( $b=$ diameter of hydrodynamic segment, $a^{\prime}=$ length of links connecting segments. $N+1=$ number of links in a chain).

\section{a. Method 1A.}

Flory's viscosity parameters $\Phi\left(=[\eta] M_{w} /\left(q_{w, z} 6^{3 / 2}\right.\right.$ $\left\langle\mathrm{S}^{2}\right\rangle_{z}{ }^{3 / 2}, q_{w, z}=$ correction factor of the polydispersity) for CDA solutions in acetone and THF at $25^{\circ} \mathrm{C}$ is listed in Table II and plotted against $M_{w}$ in Figure 7. Here, $q_{w, z}$ was calculated by assuming the Schulz-Zimm distribution for the CDA fractions used. Obviously, $\Phi$ is smaller than the theoretical value for the nondraining limit in theta solvent $\left(\Phi_{0}(\infty)=2.87 \times 10^{23}\right)$, having a positive molecular weight dependence, expressed by the relation of semiempirical nature

$$
\Phi=K_{\Phi} M^{a \Phi}
$$

For CDA, we obtain $a_{\Phi}=0.716$ in acetone and 0.105 in THF. The former is about three times larger than that theoretically calculated from $X=1.48$ and the excluded volume effect parameter $a_{1}(\equiv 3 \varepsilon$, where $\varepsilon$ is defined by eq 13$)=0.10$ with an assumption of the gaussian chain ( $a_{2}$ (see, eq 14$)=0$ ) and the latter is in good agreement with an expected value from $X$ and $a_{1}$. The experimental fact of $a_{\Phi}>0$ has been investigated previously for various other cellulose derivatives. $^{24}$

Next, we attempted an indirect estimation of the linear expansion factor $\alpha_{\mathrm{s}}\left(=\left\langle\mathrm{S}^{2}\right\rangle^{1 / 2} /\left\langle\mathrm{S}^{2}\right\rangle_{0}{ }^{1 / 2}\right.$, $\left\langle\mathrm{S}^{2}\right\rangle_{0}{ }^{1 / 2}=$ radius of gyration at unperturbed state) from $M_{w}, A_{2}$ and $\left\langle\mathrm{S}^{2}\right\rangle_{z}{ }^{1 / 2}$ data through use of a penetration function $\phi$ due to Kurata-FukatsuSotobayashi-Yamakawa (KFSY) theory ${ }^{25}$ (here, $\left\langle\mathrm{S}^{2}\right\rangle_{z}{ }^{1 / 2}$ was converted to $\left\langle\mathrm{S}^{2}\right\rangle_{w}{ }^{1 / 2}$ )

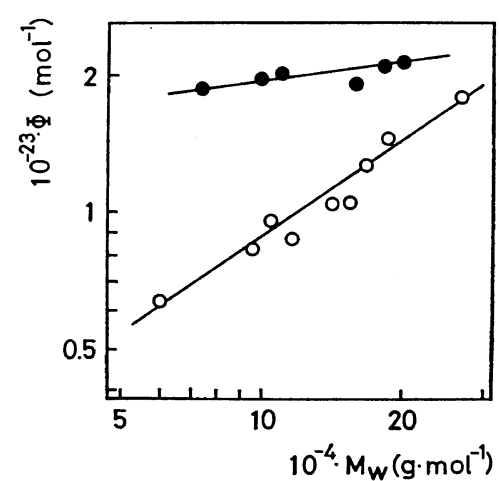

Figure 7. Molecular weight dependence of the Flory's viscosity parameter $\Phi$ for cellulose diacetate fractions in acetone (O) and in tetrahydrofuran (THF) (O) at $25^{\circ} \mathrm{C}$. 


\section{K. Kamide, T. TeraKawa, and Y. MiYazaki}

Table II. Flory's viscosity parameter $\Phi$, linear expansion factor $\alpha_{\mathrm{s}}$, and draining parameter $X$ for cellulose diacetate in acetone and in $\mathrm{THF}$ at $25^{\circ} \mathrm{C}$

\begin{tabular}{|c|c|c|c|c|c|c|}
\hline \multirow[b]{2}{*}{ Polymer code } & \multicolumn{3}{|c|}{ Acetone } & \multicolumn{3}{|c|}{ THF } \\
\hline & $\Phi \times 10^{-23}$ & $\alpha_{\mathrm{s}}^{\mathrm{a}}$ & $X$ from eq 11 & $\Phi \times 10^{-23}$ & $\alpha_{\mathrm{s}}^{\mathrm{a}}$ & $X$ from eq 11 \\
\hline EF 2-10 & $0.63_{5}$ & 1.01 & 0.52 & - & - & - \\
\hline EF 3-6 & - & - & - & 1.87 & 1.05 & 4.6 \\
\hline EF 2-11-1 & $0.83_{2}$ & 1.02 & 0.86 & - & - & - \\
\hline EF 3-8 & - & - & - & 1.98 & 1.08 & 6.4 \\
\hline EF 3-10 & $0.96_{0}$ & 1.02 & 0.90 & 2.01 & 1.05 & 6.0 \\
\hline EF 2-14 & $0.89_{3}$ & 1.01 & 0.88 & - & - & - \\
\hline EF 3-12 & 1.04 & 1.02 & 1.10 & 1.93 & 1.07 & 5.8 \\
\hline EF $2-15$ & 1.04 & 1.03 & 1.10 & - & - & - \\
\hline EF 3-13 & 1.27 & 1.04 & 1.50 & 2.10 & 1.09 & 8.5 \\
\hline EF 3-14 & 1.45 & 1.04 & 2.25 & 2.13 & 1.04 & 8.2 \\
\hline EF 3-15 & 1.78 & 1.09 & 4. & - & - & - \\
\hline
\end{tabular}

a Trifluoroethanol.

$$
\begin{gathered}
\phi=0.746 \times 10^{-25} A_{2} M^{2} /\left\langle\mathrm{S}^{2}\right\rangle^{3 / 2}=\bar{z} h_{0}(\bar{z}) \\
\text { where } \bar{z} h_{0}(\bar{z})=(1 / 5.047)\left[1-(1+0.683 \bar{z})^{-7.39}\right] \\
\bar{z}=z / \alpha_{\mathrm{s}}{ }^{3}=(3 / 2 \pi)^{3 / 2}\left(\alpha_{\mathrm{s}}{ }^{-3}\right) B A^{-3} M^{1 / 2} \\
\alpha_{\mathrm{s}}{ }^{3}=1+1.73 z \\
A=\left(6\left\langle\mathrm{~S}^{2}\right\rangle_{0} / M\right)^{1 / 2}
\end{gathered}
$$

$A$ and $B$ are the short- and long-range interaction parameters, respectively. The $\alpha_{\mathrm{s}}$ value thus calculated is in the vicinity of unity, as tabulated in the third and sixth columns of Table II.

Using $\Phi$ and $\alpha_{\mathrm{s}}$ data, $X$ can be determined by eq 9

$$
\Phi=\Phi_{0}(X) \alpha_{\mathrm{s}}^{-[3-n(x)]}
$$

where $\Phi_{0}(X)$ and $n(X)$ have the usual meaning. ${ }^{22}$ The $X$ value for CDA fractions in acetone and in THF is given in the fourth and seventh columns of Table II. In acetone, $X$ increases gradually with $M_{w}$ from 0.52 to $4.2 . \quad X=1.48$ and 6.6 are obtained as average for acetone and THF, respectively.

Stein and Doty ${ }^{1}$ determined $M_{w}, A_{2}$ and $\left\langle\mathrm{S}^{2}\right\rangle_{z}{ }^{1 / 2}$ of the fractions in acetone, whose $[\eta]$ was also measured by Badgley and Mark. ${ }^{14}$ By use of these data, we obtain $X=0.04-0.07$. Using data from Tanner and Berry's work ${ }^{2}$ for CDA in THF and in TFE at $25^{\circ} \mathrm{C}$, the $X$ value as evaluated by Method $1 \mathrm{~A}$ is found to be 0.70 in THF and $0.27-0.8$ (average, 0.46 ) in TFE. It will be noted that contamination by gel-like materials leads to errorneously low $X$ values.

\section{b. Method 1B.}

The exponent $a$ in eq 1 and the expont $a_{\mathrm{s}}$ in the relation between the sedimentation coefficient at infinite dilution $s_{0}$ and $M$,

$$
s_{0}=K_{\mathrm{s}} M^{a_{\mathrm{S}}}
$$

are related to $X$ by the relation ${ }^{23}$

$$
a=0.5+\nu(X)+n(X) \varepsilon+1.5 a_{2}
$$

and $^{23}$

$$
3 a_{\mathrm{s}}+a-2.0=\nu(X)-3 \mu(X)+[n(X)-3 m(X)] \varepsilon
$$

where

$$
\begin{gathered}
\varepsilon=\mathrm{d} \ln \alpha_{\mathrm{s}} / \mathrm{d} \ln M \\
a_{2}=\mathrm{d} \ln \left(\left\langle\mathrm{S}^{2}\right\rangle_{0} / M\right) / \mathrm{d} \ln M
\end{gathered}
$$

$\nu(X), \mu(X)$ and $m(X)$ are functions of $X$ given by Kurata-Yamakawa (KY) theory. ${ }^{22} \quad X$ and $\varepsilon$ can determined from $a$ and $a_{\mathrm{s}}$ by use of eq 11 and 12, where $a_{2}$ is practically zero or known in advance. Assuming $a_{2}=0$, this method was applied to the data of Holmes and Smith (HS), ${ }^{26}$ Golbev and Frenkel (GF), ${ }^{27}$ and Ishida, et al. (I), ${ }^{28}$ who employed the same fractions as those in this paper for sedimentation velocity measurement. The $X$ value is evaluated as $0.75,2.5$, and 1.4 for $\mathrm{HS}, \mathrm{GF}$, and I works, respectively. If we put $a_{2}=-0.471$ (see Table IV) for the data from Ishida, et al.'s work on the CDA fractions in acetone ( $a=0.616$ and $a_{\mathrm{s}}=0.384$ ) into eq 11 , we obtain $X=0.24$ in place of 1.4 .

c. Method $1 \mathrm{C}$.

The exponent $a_{\mathrm{d}}$ in the relation 


$$
D_{0}=K_{\mathrm{d}} M^{a_{\mathrm{d}}}
$$

( $D_{0}=$ diffusion coefficient at infinite dilution) is related to $a$ and $X$ by the formula ${ }^{23}$

$$
a-3 a_{\mathrm{d}}+1=\nu(X)-3 \mu(X)+(n(X)-3 m(X)) \varepsilon
$$

Subsitution of numerical values for $a$ and $a_{\mathrm{d}}$ into eq 11 and 16 enables us to determine $X$ and $\varepsilon$ if $a_{2}$ is predetermined. Holmes and $\mathrm{Smith}^{26}$ carried out the diffusion measurement in acetone for the same CDA fractions as those cited in Method 1B. $a_{\mathrm{d}}=0.70$ is obtained from their data. Using $a=0.98$ and $a_{\mathrm{d}}=0.70$ and assuming $a_{2}=0$, we obtain $X=0.74$.

\section{d. Method 1E}

We can determine $X$ from [ $\eta]$ and the concentration dependence of sedimentation coefficient $k_{\mathrm{s}}$ by using the relation ${ }^{29}$

$$
k_{\mathrm{s}} /[\eta]=(55 / 8) N_{\mathrm{A}} \Phi_{0}(X)^{1 / 3} P_{0}(X)^{-1}\left(16200 \pi^{2}\right)^{-1}
$$

where

$$
k_{\mathrm{s}}=\left\{\left(s_{0} / s\right)-1\right\} / c
$$

$s=$ sedimentation coefficient at concentration $c$, $P_{0}(X)=$ function of $X$ given by $\mathrm{KY}$ theory. ${ }^{22}$
Equation 17 holds in the range $\alpha_{\mathrm{s}}<2$.

Ishida and Kamide, et al. ${ }^{28}$ determined $s$ for the same CDA fractions as those used here in acetone as a function of $c$. Using their data we obtain $X=0.27-0.44$ (average, 0.32 ).

The $X$ values thus determined are in the range of $0.3 \sim 7$ as recorded in Table III, suggesting that the partially free draining effect on the viscosity, sedimentation and diffusion coefficients can never be ignored, particularly so in acetone. We have already demonstrated for cellulose and amylose and their derivatives that the $X$ value is almost invariably less than $2 .^{24}$

\section{Unperturbed Chain Dimensions}

Unperturbed chain dimensions (UCD), expressed by $A$ in eq 8, can be determined from data on dilute solution properties in non- $\theta$ solvent by following methods.

a. Method 2B

$\left\langle\mathrm{S}^{2}\right\rangle_{0}{ }^{1 / 2}$ is calculated from the experimental $\left\langle\mathrm{S}^{2}\right\rangle_{w}{ }^{1 / 2}$ data and $\alpha_{\mathrm{s}}$, which is estimated from $\phi$

\begin{tabular}{|c|c|c|c|c|c|c|c|}
\hline \multirow{2}{*}{ Solvent } & \multirow{2}{*}{ DS } & \multirow{2}{*}{ Temp, ${ }^{\circ} \mathrm{C}$} & \multicolumn{4}{|c|}{$X$} & \multirow{2}{*}{ Remarks } \\
\hline & & & Method 1A & Method 1B & Method 1C & Method $1 \mathrm{E}$ & \\
\hline \multirow{7}{*}{ Acetone } & 2.45 & 25 & $0.52-4.2$ & - & - & - & This work \\
\hline & & - & $(1.48)^{\mathrm{b}}$ & $1.4[0.24]^{\mathrm{c}}$ & - & $0.27-0.44$ & Ishida-Kamide, et al. ${ }^{28}$ \\
\hline & & - & - & & & $(0.32)$ & \\
\hline & 2.43 & 25 & $0.04-0.07$ & - & - & - & Stein, et al. ${ }^{1,14}$ \\
\hline & & - & $(0.06)$ & & & & \\
\hline & 2.33 & 20 & - & 0.74 & 0.74 & - & Holmes-Smith ${ }^{26}$ \\
\hline & $\begin{array}{r}2.33- \\
2.37\end{array}$ & 25 & - & 1.8 & - & - & Golbev-Frenkel $^{27}$ \\
\hline \multirow[t]{2}{*}{ THF } & 2.45 & 25 & $(4.6-8.5(6.6)$ & - & - & - & This work \\
\hline & & & 0.7 & - & - & - & Tanner-Berry ${ }^{2}$ \\
\hline $\mathrm{TFE}^{\mathrm{a}}$ & 2.45 & 20 & $\begin{array}{c}0.27-0.8 \\
(0.46)\end{array}$ & - & - & - & Tanner-Berry ${ }^{2}$ \\
\hline
\end{tabular}
through use of eq 4-7. The value of $A$, that is $\left\langle\mathrm{S}^{2}\right\rangle_{w_{0}} / M$, thus obtained in acetone exhibits a

Table III. Draining parameter $X$ of CDA

a Trifluoroethanol. ${ }^{\mathrm{b}}$ Number in parenthesis means average. ${ }^{\mathrm{c}}$ Number in bracket denotes the value when $a_{2}$ is taken into account.

Table IV. Various parameters employed for evaluation of unperturbed chain dimensions of cellulose diacetate

\begin{tabular}{lcccccc}
\hline Solvent & $a$ in eq 1 & $a_{\Phi}$ in eq 3 & $\begin{array}{c}K_{\Phi} \times 10^{-24} \text { in } \\
\text { eq } 3\end{array}$ & $a_{2}$ in eq 14 & \multicolumn{2}{c}{$a_{1}$} \\
\cline { 6 - 7 } & & & & eq $11^{\prime}$ & eq 29 \\
\hline Acetone & $0.61_{6}$ & $0.71_{6}$ & $2.26 \cdot 10^{-5}$ & -0.471 & $0.10_{7}$ & 0.130 \\
THF & $0.68_{8}$ & $0.10_{5}$ & 0.0573 & 0 & $0.08_{3}$ & 0.150 \\
\hline
\end{tabular}




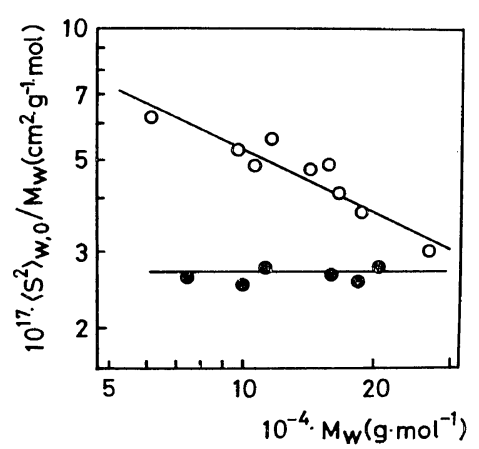

Figure 8. Molecular weight dependence of $\left\langle\mathrm{S}^{2}\right\rangle_{0} / M_{w}$, as determined by method $2 \mathrm{~B}$, of cellulose diacetate in acetone $(\bigcirc)$ and in tetrahydrofuran $\left(\right.$ ) at $25^{\circ} \mathrm{C}$.

rather striking molecular weight dependence as shown in Figure 8 and $a_{2}$, defined by eq 14, amounts to $-0.471, a_{2}<0$ is not unusual for cellulose derivatives. ${ }^{24}$ The average value of $A$ is found to be $1.68 \times 10^{-8} \mathrm{~cm}$. In contrast to this, the $A$ value in THF $1.26 \times 10^{-8} \mathrm{~cm}$ is almost independent of $M_{w}$ (i.e., $a_{2}=0$ ). The negative correlationships between $a_{\Phi}$ and $a_{2}$ have been demonstrated for numerous cellulose and amylose derivatives. ${ }^{24}$

b. Method 2C

Plot of $\left\langle\mathrm{S}^{2}\right\rangle_{w}{ }^{3 / 2} / M_{w}{ }^{3 / 2}$ vs. $M_{w}{ }^{1 / 2}$ (Baumann plot) according to eq $19^{30}$

$$
\left\langle\mathrm{S}^{2}\right\rangle^{3 / 2} / M^{3 / 2}=A^{3} / 6^{3 / 2}+\left[1 /\left(4 \pi^{3 / 2}\right)\right] B M^{1 / 2}
$$

yields $\left\langle\mathrm{S}^{2}\right\rangle_{w, 0}^{3 / 2} / M_{w}{ }^{3 / 2}$ as an intercept at $M_{w}{ }^{1 / 2}=0$ as

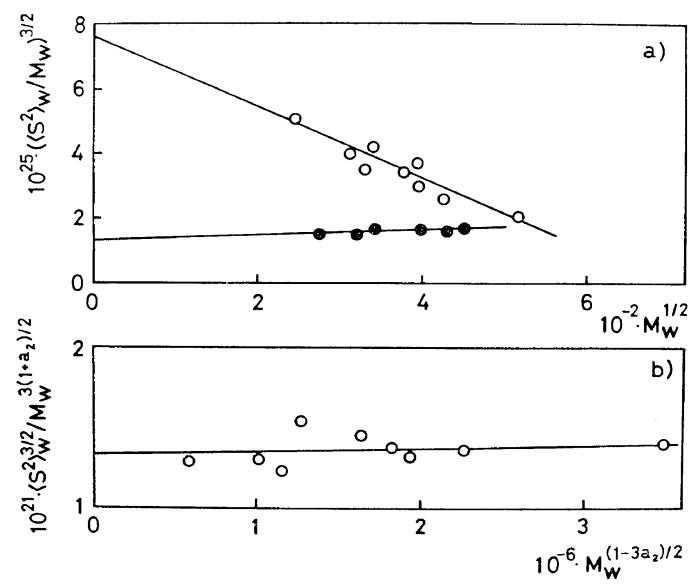

Figure 9. Baumann plot (a) and Baumann-KamideMiyazaki (BKM) plot (b) of cellulose diacetate (CDA) in acetone $(O)$ and in tetrahydrofuran ( ) at $25^{\circ} \mathrm{C}$. In BKM plot $a_{2}=-0.471$ is used for in acetone. shown in Figure 9a. A line can be drawn through all the data points and $A$ value is found to be $2.14 \times 10^{-8} \mathrm{~cm}$ in acetone and $1.24 \times 10^{-8} \mathrm{~cm}$ in THF, respectively. The slope of the plot is theoretically expected to reflect the sign of the long-range interaction parameter $B$ accordingly $A_{2}$, see eq 32 , being negative when $A_{2}<0$. However, a large negative slope of the plot for CDA in acetone sharply contradicts with the experimental fact of $A_{2}>0$. This inconsistency can be ressolved only by taking into account $a_{2} \neq 0$ in the original Baumann's equation [eq 19]. The $A$ value thus estimated by this method for CDA in acetone is less accurate.

c. Method 2D

When the polymer chain in the unperturbed state is nongaussian (i.e., $a_{2} \neq 0$ ) as in the case of CDA in acetone, eq 19 may be modified as ${ }^{24}$

$$
\left\langle\mathrm{S}^{2}\right\rangle^{3 / 2} / M^{3 / 2\left(1+a_{2}\right)}=K_{0}^{3 / 2}+\frac{1}{4 \pi^{3 / 2}} B M^{\left(1-3 a_{2}\right) / 2}
$$

where

$$
K_{0}=\left(\left\langle\mathrm{S}^{2}\right\rangle_{0} / M\right) / M^{a_{2}} .
$$

Thus, from the graph of $\left\langle\mathrm{S}^{2}\right\rangle_{w}^{3 / 2} / M_{w}^{3 / 2\left(1+a_{2}\right)}$ as a function of $M_{w}{ }^{\left(1-3 a_{2}\right) / 2}=0$ (Baumann-Kamide-Miyazaki (BKM) plot), the parameter $K_{0}$ may be obtained as an intercept at $M_{w}{ }^{\left(1-3 a_{2}\right) / 2}=0$. This plot is, of course, prerequisite $a_{2}$. Using $a_{2}=-0.471$, BKM plot for CDA in acetone is demonstrated in Figure $9 \mathrm{~b}$, from which $K_{0}=1.18 \times 10^{-14} \mathrm{~cm}^{2}$ is estimated.

\section{d. Method 2E}

Stockmayer and Fixman (SF) plot according to eq $22^{31}$

$$
[\eta] / M^{1 / 2}=K+2(3 / 2 \pi)^{3 / 2} \Phi_{0}(\infty) B M^{1 / 2}
$$

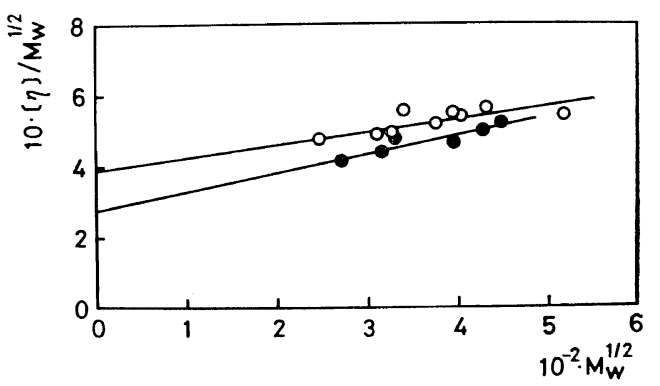

Figure 10. The Stockmayer-Fixman plot according to eq 22 for cellulose diacetate in acetone $(O)$ and in tetrahydrofuran (O) at $25^{\circ} \mathrm{C}$. 
Dilute Solution Properties of Cellulose Diacetate

where

$$
K=\Phi_{0}(\infty)\left(6\left\langle\mathrm{~S}^{2}\right\rangle_{0} / M\right)^{3 / 2}
$$

is applicable in the case of $a_{\Phi}=0$ and $a_{2}=0$. SF plots for CDA in acetone and THF are graphed in Figure 10. Resonable straight lines for each solution are obtainable. $A=1.10 \times 10^{-8}$ and 0.99 $\times 10^{-8}$ are evaluated in acetone and THF, respectively, where $\Phi_{0}(\infty)$ was assigned the value $2.87 \times 10^{23}$. These values are less reliable, because for the CDA solution $a_{\Phi}>0$ and $a_{2} \leq 0$ are observed.

\section{e. Method 2F}

According to Kamide, Kawai, and their coworkers, ${ }^{32,33}$ there exists a theoretical relationships between $K_{m}$ and $a$ in eq 1 in the case of $a_{\Phi}=0$ and $a_{2}=0$ as

$$
\begin{aligned}
& -\log K_{m}+\log \left[1+2\left\{(a-0.5)^{-1}-2\right\}^{-1}\right] \\
& =-\log K+(a-0.5) \log M_{0}
\end{aligned}
$$

where $M_{0}=$ the geometric mean of the upper and lower molecular weight limit $\left(M_{1} \cdot M_{2}\right)^{1 / 2}$, in which eq 1 holds. A plot of the left-hand side of eq 24 as a function of a -0.5 (Kamide plot) should be linear, with a slope equal to $\log M_{0}$. The Kamide plot for CDA in acetone and THF is illustrated in Figure 11. $K=0.399$ (i.e., $A=1.2 \times$ $\left.10^{-8} \mathrm{~cm}\right)$ in acetone and $0.289\left(A=1.00 \times 10^{-8} \mathrm{~cm}\right)$ in THF are determined by method $2 \mathrm{~F}$.

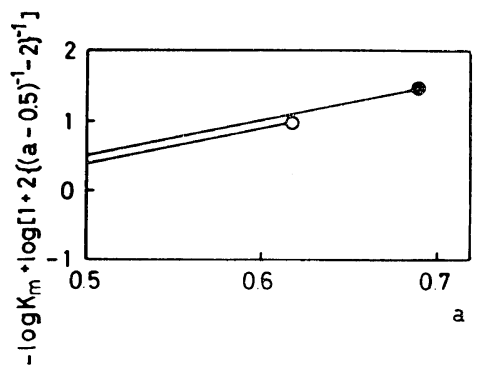

Figure 11. Kamide plot according to eq 24 for cellulose diacetate in acetone $(\mathrm{O})$ and in tetrahydrofuran (-) at $25^{\circ} \mathrm{C}$. The lines, which have slopes of $1 / 2$ $\log \left(M_{1} M_{2}\right)$, are constructed to pass through each data point.

\section{f. Method 2G}

In the case of $a_{\Phi} \neq 0$ and $a_{2} \neq 0$, the well-known Flory-Fox viscosity equation can be rewritten in the form ${ }^{24}$

$$
\begin{aligned}
& {[\eta] / M^{0.5+a_{\Phi}+1.5 a_{2}}} \\
& \quad=6^{3 / 2} K_{\Phi} K_{0}^{3 / 2}+0.66 K_{\emptyset} B M^{0.5-1.5 a_{2}}
\end{aligned}
$$

Evidently, eq 25 reduces to eq 22 when $a_{\Phi}=a_{2}=0$. It was found in a previous paper that the intrinsic viscosity of cellulose, amylose and their derivatives conforms very well to eq $25 .^{24}$ Plot of $\left.[\eta]\right] /$ $M_{w}{ }^{0.5+a_{\Phi^{+1.5}}}$ vs. $M_{w}{ }^{0.5-1.5 a_{2}}$ (Kamide-Miyazaki (KM) plot) for a given solvent results in a straight line and it is extrapolation to $M_{w}{ }^{1 / 2}=0$ should give $6^{3 / 2} K_{\Phi} K_{0}^{3 / 2}$ (accordingly, $K_{0}$ ). By using the values of $a_{\Phi}$ and $a_{2}$ together with $K_{\Phi}$ summerized in Table VI, KM plot is constructed as shown in Figure 12, from which $K_{0}=1.16 \times 10^{-14} \mathrm{~cm}^{2}$ in acetone and $2.50 \times 10^{-17} \mathrm{~cm}^{2}$ in THF are estimated.

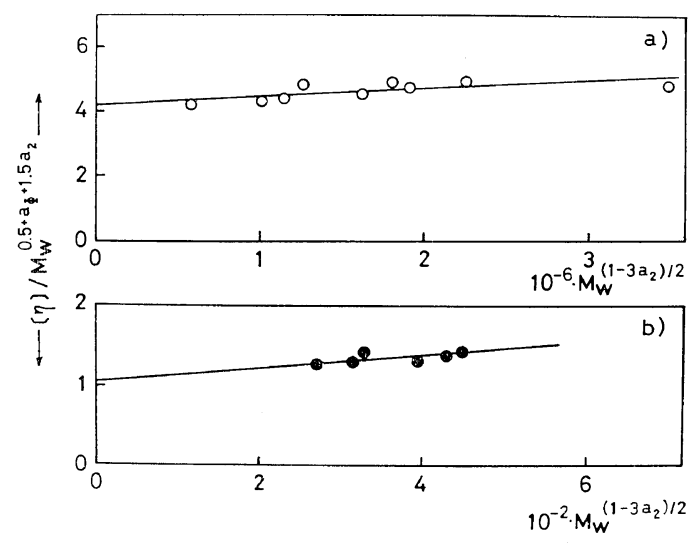

Figure 12. The Kamide-Miyazaki plot according to eq 25 for cellulose diacetate in acetone $(O)$ and in tetrahydrofuran (THF) $(\bullet)$ at $25^{\circ} \mathrm{C}$. The values of $a_{\Phi}$ and $a_{2}$ in Table VI are used.

\section{g. Method $2 \mathrm{H}$}

Assuming $a_{2}=0$ and $a_{1}\left(=3 \mathrm{~d} \log \alpha_{\mathrm{s}} / \mathrm{d} \log M=\right.$ $3 \varepsilon)=0$, Tanner and Berry derived eq $26^{2}$

$$
M^{1 / 2} /[\eta]=\left(1+A^{\prime} M^{-1 / 2}\right) /\left(K^{\prime} A^{3}\right)
$$

where $K^{\prime}$ and $A^{\prime}$ are parameters depending on the models used. The plot of $M_{w}{ }^{1 / 2}[\eta]$ against $M_{w}{ }^{-1 / 2}$ (Tanner-Berry plot) gives $A$ from an ordinate at $M_{w}{ }^{1 / 2}=0$. Figure 13 shows the Tanner-Berry plot for CDA in acetone and THF. We obtained $K^{\prime}=(2.87 / 1.295) \times 10^{23}$ for the former and $K^{\prime}=$ $2.87 \times 10^{23}$ for the latter from Table III in this paper and Table VIII of ref 2 . $A$ is found to be $1.45 \times 10^{-8} \mathrm{~cm}$ in acetone and $1.37 \times 10^{-8} \mathrm{~cm}$ in THF. For CDA in THF, Tanner and Berry have obtained $A=1.91 \times 10^{-8} \mathrm{~cm}$ this value is 


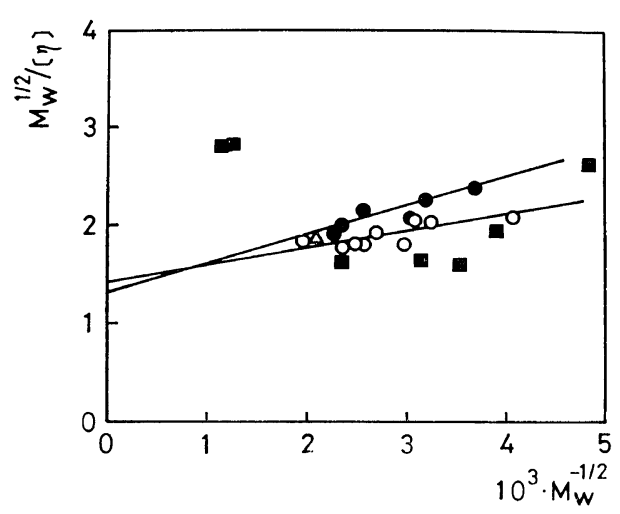

Figure 13. The Tanner-Berry plot according to eq 26 for cellulose diacetate in acetone (open mark) and in tetrahydrofuran (closed mark) at $25^{\circ} \mathrm{C}: \bigcirc$ and this work; $\mathbf{n}$, data from Tanner and Berry's workt. ${ }^{2}$

calculated from Table $\mathrm{V}$ of ref 2), which is about $40 \%$ larger than the value we obtained. The plot of their data scatters very much as shown in Figure 13 as closed rectangular, and it is extrapolation contains much uncertainity.

Table $\mathrm{V}$ summerizes the $K_{0}, A$ values together with the $B$ values as determined by Methods $2 \mathrm{~B}$ $2 \mathrm{H}$. In the case of $a_{2} \neq 0$, the $A$ value is calculated for $M_{w}=1 \times 10^{5}$. Table $\mathrm{V}$ also includes the conformation parameter $\sigma\left(=A / A_{f}, A_{f}=A\right.$ of a hypothetical chain with free internal rotation) and characteristic ratio $C_{\infty}$.

If the $A$ values estimated by Methods 2B, $\cdots$,
$2 \mathrm{H}$ are designated as $A_{(2 \mathrm{~B})}, \cdots, A_{(2 \mathrm{H})}$ for convenience, the following relations hold experimentally

$$
\begin{gathered}
A_{(2 \mathrm{C})}>A_{(2 \mathrm{~B})} \simeq A_{(2 \mathrm{D})} \simeq A_{(2 \mathrm{G})} \gg A_{(2 \mathrm{H})}>A_{(2 \mathrm{E})} \simeq A_{(2 \mathrm{~F})} \\
\text { in acetone } \\
A_{(2 \mathrm{H})}>A_{(2 \mathrm{~B})} \simeq A_{(2 \mathrm{C})} \simeq A_{(2 \mathrm{G})} \gg A_{(2 \mathrm{E})} \simeq A_{(2 \mathrm{~F})} \\
\text { in THF }
\end{gathered}
$$

From a theoretical view point, in the case of $a_{2} \neq 0$ and $a_{\Phi} \neq 0$, methods $2 \mathrm{~B}, 2 \mathrm{D}$ and $2 \mathrm{G}$ are expected to be the most reliable methods presently available for estimating the $A$ value and in the case of $a_{2}=0$ and $a_{\mathscr{\Phi}} \neq 0$, methods $2 \mathrm{~B}, 2 \mathrm{C}$, and $2 \mathrm{G}$ are recommended to employ. ${ }^{24}$ The former corresponds to solution of CDA in acetone and the latter to $\mathrm{CDA}$ solution in THF. Agreement between methods $2 \mathrm{E}$ and $2 \mathrm{~F}$ is excellent. However, the values estimated by these methods are $35 \%$ smaller than those by methods $2 \mathrm{~B}, 2 \mathrm{C}$ (or 2D), and $2 \mathrm{G}$, owing to the neglect of $a_{2}$ and $a_{\Phi}$. Method $2 \mathrm{H}$ overestimates or underestimates the $A$ value depending on the magnitude of $a_{1}+1.5 a_{2}{ }^{34}$ In fact, in acetone $a_{1}+1.5 a_{2}$ is negative $(-0.6)$, and Method $2 \mathrm{H}$ is thus expected to underestimate $A$. In contrast to this, in THF $a_{1}+1.5 a_{2}$ is positive (0.08) and so, Method $2 \mathrm{H}$ may overestimate the $A$ value. It has been observed that when $a_{2}<0$ Method $2 \mathrm{C}$ has a tendency to overestimate $A$ (see, Table $4 \mathrm{a}$ and $\mathrm{b}$ of ref 24 ). The relative

\begin{tabular}{|c|c|c|c|c|c|c|c|c|c|c|}
\hline \multirow[b]{2}{*}{ Method $^{a}$} & \multicolumn{3}{|c|}{ Acetone } & \multicolumn{7}{|c|}{ THF } \\
\hline & $\begin{array}{c}K_{0} \times 10^{16} \\
\mathrm{~cm}^{2}\end{array}$ & $\begin{array}{c}A \times 10^{8}, \\
\mathrm{~cm}\end{array}$ & $\begin{array}{c}B \times 10^{27} \\
\mathrm{~cm}^{2}\end{array}$ & $\sigma^{\mathrm{c}}$ & $C_{\infty}^{\mathrm{d}}$ & $\begin{array}{c}K_{0} \times 10^{16}, \\
\mathrm{~cm}^{2}\end{array}$ & $\begin{array}{c}A \times 10^{8}, \\
\mathrm{~cm}\end{array}$ & $\begin{array}{c}B \times 10^{27}, \\
\mathrm{~cm}^{3}\end{array}$ & $\sigma^{\mathrm{c}}$ & $C_{\infty}{ }^{\mathrm{d}}$ \\
\hline 2B $\left(\alpha_{\mathrm{s}}\right.$ from $\left.\phi\right)$ & - & 1.66 & - & 3.44 & 24.7 & - & 1.23 & - & 2.56 & 14.1 \\
\hline $2 \mathrm{C}\left(a_{2}=0\right)$ & - & 2.14 & -24.5 & 4.44 & 40.1 & - & 1.24 & 1.67 & 2.58 & 13.6 \\
\hline $2 \mathrm{D}\left(a_{2} \neq 0\right)$ & 118 & $1.77^{\mathrm{b}}$ & 0.90 & 3.69 & 27.7 & - & - & - & - & - \\
\hline $2 \mathrm{E}\left(a_{2}=a_{\Phi}=0\right)$ & - & 1.10 & 1.90 & 2.28 & 10.6 & - & 0.99 & 2.71 & 2.05 & 8.6 \\
\hline $2 \mathrm{~F}\left(a_{2}=a_{\Phi}=0\right)$ & - & 1.12 & - & 2.32 & 10.9 & 一 & 1.00 & - & 2.08 & 8.9 \\
\hline $2 \mathrm{G}\left(a_{2} \neq 0, a_{\Phi} \neq 0\right)$ & 116 & $1.75^{b}$ & 1.56 & 3.63 & 27.0 & 0.250 & $1.23^{\mathrm{b}}$ & 2.11 & 2.55 & 13.2 \\
\hline $\begin{array}{c}2 \mathrm{H}\left(a_{1}=a_{2}=0\right. \\
\left.a_{\Phi} \neq 0\right)\end{array}$ & - & 1.45 & - & 3.00 & 18.4 & - & 1.37 & - & 2.85 & 16.6 \\
\hline $\begin{array}{l}\text { Most probable } \\
\text { value }\end{array}$ & & 1.73 & & 3.59 & 26.3 & & 1.23 & & 2.56 & 13.5 \\
\hline
\end{tabular}
order of the $A$ value, as determined by the various

Table V. Unperturbed chain dimensions $A$, long-range interaction parameter $B$, conformation parameter $\sigma$ and characteristic ratio $C_{\infty}$ of cellulose diacetate in acetone and THF at $25^{\circ} \mathrm{C}$

a Same notations as those in ref 24 are used in order to avoid confusion.

b $A$ value at $M_{w}=1 \times 10^{5}$.

c $\mathrm{C} 1$ chair conformation is assumed.

d The mean bond length $l=5.47 \AA$ is used. 
methods, agrees well with the results obtained for cellulose, amylose and their derivatives. ${ }^{24}$ Therefore, the most reliable $A$ value $\left(A_{(\mathrm{m})}\right)$ can be defined as $\left(A_{(2 \mathrm{~B})}+A_{(2 \mathrm{D})}+A_{(2 \mathrm{C})}\right) / 3$ for $\mathrm{CDA}$ in acetone and $\left(A_{(2 \mathrm{~B})}+A_{(2 \mathrm{C})}+A_{(2 \mathrm{G})}\right) / 3$ for $\mathrm{CDA}$ in THF, respectively. $A_{(\mathrm{m})}$ values thus calculated are 1.73 in acetone and 1.23 in THF and are listed also in Table V. The value of $\sigma$ corresponding to $A_{(\mathrm{m})}$ is not unusually high as compared with other cellulose derivatives. ${ }^{24}$

We thus conclude that cellulose acetate is a semi-flexible polymer, whose flexibility is remarkably influenced by the solvent nature, as was observed in cellulose, cellulose tricarbanilate and amylose tricarbanilate. $^{24}$ That is, CDA is considerably less flexible in acetone than in THF, suggesting that there is a specific solvent effect, like a temperature effect or solvation, on a shortrange interaction.

The contribution of the excluded volume effect to the exponent $a, a_{1}(\equiv 3 \varepsilon)$ can be roughly estimated from $a, a_{\Phi}$, and $a_{2}$ by eq $11^{\prime}$

$$
a=0.5+a_{\Phi}+a_{1}+1.5 a_{2}
$$

The value of $a_{1}$ thus determined by eq $11^{\prime}$ is 0.107 in acetone and 0.083 in THF as summerized in the column of Table IV.

The $a_{1}$ value can be also estimated by using an alternative equation

$$
\lambda^{\prime}=a_{2}+2 \varepsilon
$$

where

$$
\lambda^{\prime}=\mathrm{d} \ln \left(\left\langle\mathrm{S}^{2}\right\rangle / M\right) / \mathrm{d} \ln M
$$

$\lambda^{\prime}$ is found to be -0.400 and 0.056 from eq $\mathrm{c}$ and $\mathrm{d}$; thus, we obtain $a_{1}=0.130$ in acetone and 0.150 in THF. Both are slightly larger than those calculated from eq $11^{\prime}$. The fact that the exponent $a_{1}$ values are not as large as $0.2-0.3$ confirms that acetone and THF are not good solvent.

Putting $a_{1}$ values obtained in this manner into the modified Voek's equation ${ }^{35,36}$

$$
a_{1}+0.5=\left(4 \alpha_{\mathrm{s}}^{2}-3\right) /\left(5 \alpha_{\mathrm{s}}^{2}-3\right)
$$

$\alpha_{s} \simeq 1.1$ and 1.18 are calculated for CDA in acetone and THF, respectively. Those values are not so different from those estimated through use of the penetration function $\phi$.

When the values of $A$ and $B$ are obtainable by Methods 2C, 2D, 2E, and 2G, we can calculate $A_{2}$ from $A, B$, and the experimental $\left\langle\mathrm{S}^{2}\right\rangle_{w}$ value by using the relation. ${ }^{37,38}$

$$
A_{2}=\left(N_{\mathrm{A}} / 2\right) B h_{0}(z)
$$

In Figure 5, full (Method 2C), dotted (Method 2D), broken (Method 2E), and chain (Method 2G) lines are thus calculated by using eq 32 and 5 from $A$ and $B$ in Table $\mathrm{V}$ and $\left\langle\mathrm{S}^{2}\right\rangle_{z}{ }^{1 / 2}$ in Table $\mathrm{I}$. The $A_{2}$ value calculated by Method $2 \mathrm{C}$ for acetone is a large negative value and is not shown in the figure. It is clear that Method $2 \mathrm{G}$ gives the best fit for the experimental data. Consequently, the methods used here prove highly satisfactory for interpreting the dilute solution properties of CDA.

\section{REFERENCES}

1. R. S. Stein and P. Doty, J. Am. Chem. Soc., 68, 159 (1946).

2. D. W. Tanner and G. C. Berry, J. Polym. Soc., Polym. Phys., 12, 941 (1974).

3. M. Kurata, Y. Tsunashima, M. Ikeda, and K. Kamada, "Polymer Hand Book," 2nd ed, J. Brandrup and E. H. Immergut Ed., John Wiley \& Sons, New York, N.Y., 1975, IV.

4. K. Kamide, T. Terakawa, and S. Manabe, Sen-i Gakkaishi, 30, T-464 (1974).

5. K. Kamide, T. Terakawa, S. Manabe, and Y. Miyazaki, Sen-i Gakkaishi, 31, T-410 (1975).

6. S. Manabe, T. Terakawa, K. Kamide, and Y. Miyazaki, Japan Patent (Kokai), Sho 48-86364 (1973) (Reg. Nr., 885873).

7. K. Kamide and Y. Miyazaki, Makromol. Chem., 176, 1029 (1975).

8. K. Kamide and Y. Miyazaki, Makromol. Chem., 176, 1051 (1975).

9. K. Kamide and Y. Miyazaki, Makromol. Chem., 176, 3453 (1975).

10. K. Kamide, Y. Miyazaki, and T. Abe, Makromol. Chem., 177, 485 (1976).

11. K. Kamide, Y. Miyazaki, and T. Abe, Polym. J., 9, 395 (1977).

12. K. Kamide, Y. Miyazaki, T. Terakawa, and T. Abe, Polym. prepr., Japan, 26, 1160 (1977).

13. T. Ikeda and H. Kawaguchi, Rep. Prog. Polym. Sci., Jpn., 9, 23 (1966).

14. W. J. Badgley and H. Mark, J. Phys. Chem., 51, 58 (1947).

15. E. O. Kraemer, Ind. Eng. Chem., 30, 1200 (1938).

16. A. Bartovics and H. Mark, J. Am. Chem. Soc., 65, 1901 (1943).

17. A. M. Sookne and M. Harris, Ind. Eng. Chem., 37, 475 (1945).

18. H. J. Philipp and C. F. Bjork, J. Polym. Sci., 6, 549 (1951). 
19. R. J. E. Cumberbirch and W. G. Harland, J. Text. Inst., 49, T664 (1958).

20. W. R. Moore and B. M. Tidswell, J. Appl. Chem., 8, 232 (1958).

21. P. Doty, N. S. Schneider, and A. Holtzer, J. Am. Chem. Soc., 75, 754 (1953).

22. M. Kurata and H. Yamakawa, J. Chem. Phys., 29, 311 (1958).

23. K. Kamide, Makromol. Chem., 128, 197 (1969).

24. K. Kamide and Y. Miyazaki, Polym. J., 10, 409 (1978).

25. M. Kurata, M. Fukatsu, H. Sotobayashi, and H. Yamakawa, J. Chem. Phys., 41, 139 (1964).

26. F. H. Holmes and D. I. Smith, Trans. Faraday Soc., 52, 67 (1956).

27. V. M. Golbev and S. Ya. Frenkel, Vysokomol. Soedin., Ser. A, 9, 1847 (1967.)

28. K. Kamide, H. Komatsu, T. Terakawa, and S. Ishida, Collection of reprints, presented at 1977 joint Niigata Meeting of the Chemical Society of Japan, and the Society of Polymer Science, Japan
1977, p 19.

29. K. Kamide and T. Kawai, Kobunshi Kagaku, 19, 441 (1962).

30. H. Baumann, J. Polym. Sci., Polym. lett., 3, 1069 (1965).

31. W. H. Stockmayer and M. Fixman, J. Polymer Sci., Part C, 1, 137 (1963).

32. T. Kawai and K. Kamide, J. Polym. Sci., 54, 343 (1961).

33. K. Kamide and W. R. Moore, Kobunshi Kagaku, 21, 682 (1964).

34. K. Kamide and T. Terakawa, Polym. J., 10, 559 (1978).

35. J. Vokes, J. Polym. Sci., 36, 333 (1959).

36. K. Kamide and T. Kawai, Kobunshi Kagaku, 20, 506 (1963).

37. P. J. Flory, "Principles of Polymer Chemistry," Cornel Univ. Press, 1953, Chapter XIV.

38. W. H. Stockmayer, Makromol. Chem., 35, 54 (1960). 